\title{
Fragmented QRS and mortality in patients undergoing percutaneous intervention for ST-elevation myocardial infarction: Systematic review and meta-analysis
}

\author{
Napatt Kanjanahattakij ${ }^{1}$ (D) | Pattara Rattanawong ${ }^{2,3}$ (D) | Tanawan Riangwiwat $^{2}$ | \\ Narut Prasitlumkum ${ }^{2}$ (D) | Nath Limpruttidham ${ }^{2}$ | Pakawat Chongsathidkiet ${ }^{4}$ (D) | \\ Wasawat Vutthikraivit $^{5}$ (i) | Erin Crossey ${ }^{2}$
}

${ }^{1}$ Department of Medicine, Einstein Medical Center, Philadelphia, Pennsylvania

${ }^{2}$ University of Hawaii Internal Medicine Residency Program, Honolulu, Hawaii

${ }^{3}$ Faculty of Medicine Ramathibodi Hospital, Mahidol University, Bangkok, Thailand

${ }^{4}$ Department of Pathology, Duke University Medical Center, Durham, North Carolina

${ }^{5}$ Department of Medicine, Texas Tech University Health Sciences Center, Lubbock, Texas

\section{Correspondence}

Pattara Rattanawong, University of Hawaii Internal Medicine Residency Program, 1133 Waimanu st, \#2007, Honolulu, HI, 96814.

Email: pattarar@hawaii.edu

\begin{abstract}
Background: Fragmented QRS reflects disturbances in the myocardium predisposing the heart to ventricular tachyarrhythmias. Recent studies suggest that fragmented QRS (fQRS) is associated with mortality in ST-elevation myocardial infarction (STEMI) patients who underwent percutaneous coronary intervention ( $\mathrm{PCl}$ ). However, a systematic review and meta-analysis of the literature has not been done. We assessed the association between fQRS and overall mortality in STEMI patients who subsequently underwent $\mathrm{PCl}$ by a systematic review and meta-analysis.

Methods: We comprehensively searched the databases of MEDLINE and EMBASE from inception to September 2017. Studies included in our analysis were published cohort (prospective or retrospective) and case-control studies that compared overall mortality among STEMI patient with and without $\mathrm{PQRS}$ who underwent $\mathrm{PCl}$. Data from each study were combined using the random-effects, generic inverse variance method of DerSimonian, and Laird to calculate risk ratios and $95 \%$ confidence intervals.

Results: Six studies from 2014 to 2017 were included in this meta-analysis involving 2,516 subjects with STEMI who underwent $\mathrm{PCl}$ (888 fQRS and 1,628 non-fQRS). Fragmented QRS was associated with overall mortality in STEMI patients who underwent $\mathrm{PCl}$ (pooled risk ratio $=3.87 ; 95 \% \mathrm{Cl} 1.96-7.66, \mathrm{I}^{2}=43 \%$ ).

Conclusion: Fragmented QRS was associated with increased overall mortality up to threefold. Our study suggests that fQRS could be an important tool for risk assessment in STEMI patients who underwent $\mathrm{PCI}$.
\end{abstract}

\section{KEYWORDS}

Fragmented QRS, percutaneous intervention, ST elevation

\section{1 | INTRODUCTION}

Primary percutaneous coronary intervention $(\mathrm{PCl})$ has been the standard therapeutic option for ST-elevation myocardial infarction
(STEMI; Pedersen et al., 2014). Despite this effective treatment, the mortality rate in STEMI patients is still very high. In-hospital mortality ranges from $4 \%$ to $12 \%$ in European countries (Kristensen et al., 2014). The 1-year mortality rate is approximately $10 \%$ (Pedersen 
et al., 2014) in an angiographic registry. Clinical and imaging characteristics such as advanced age, Killip class, time delay to treatment, renal failure and reduced ejection fraction has been linked to increased mortality in these patients (Kristensen et al., 2014). However, there is no reliable feature on electrocardiography (ECG) to determine prognosis in STEMI patients who underwent $\mathrm{PCl}$.

Fragmented QRS complexes (fQRS) in narrow QRS complexes is defined by the presence of an additional $R$ wave $\left(R^{\prime}\right)$ or notching in the nadir of the $S$ wave, or the presence of more than one $R^{\prime}$ wave in two contiguous leads, corresponding to a major coronary artery territory (Figure 1), excluding typical bundle-branch block pattern and incomplete right bundle-branch block (Das, Khan, Jacob, Kumar \& Mahenthiran, 2006). In wide QRS complexes, the definition of fQRS complexes slightly changes based on bundle-branch block, the presence of PVCs, and paced QRS complexes. For right and left bundle-branch block pattern, fQRS complexes are defined by the presence of more than two $R$ waves $\left(R^{\prime}\right)$, more than two notches in the $\mathrm{R}$ wave, or more than two notches in the downstroke or upstroke of the $\mathrm{S}$ wave, in two contiguous leads. For PVC patterns, fQRS complexes is defined by the presence of more than two $\mathrm{R}^{\prime}$, or more than two notches in the $S$ waves, or two notches in the $R$ wave if there are more than $\mathbf{4 0} \mathrm{ms}$ apart, in two contiguous leads. For paced QRS complexes, fQRS complexes is defined by the presence of more than $2 \mathrm{R}^{\prime}$ or more than two notches in the $\mathrm{S}$ waves in two contiguous leads (Das et al., 2008).

Fragmented QRS complexes represent myocardial scar or abnormal myocardial electrical conduction. fQRS has been shown to be associated with ventricular arrhythmia events in ischemic cardiomyopathy, nonischemic cardiomyopathy (Das et al., 2010), and sudden cardiac death (Rosengarten, Scott, \& Morgan, 2015). Prior meta-analysis has shown its value in acute myocardial infarction (Gungor et al., 2016). However, there is no systematic review and meta-analysis done in patients with ST-elevation myocardial infarction (STEMI) who underwent percutaneous coronary intervention (PCI). Thus, we conducted a systematic review and meta-analysis to assess the associated between $\mathrm{fQRS}$ complexes and overall mortality in STEMI patients who underwent $\mathrm{PCl}$.

\section{2 | METHODS}

\section{1 | Search strategy}

Two investigators (NP and NL) independently searched for published studies indexed in MEDLINE and EMBASE databases from inception to June 2017 using a search strategy (Figure 2) that included the terms "fragmented QRS", "QRS fragmentation", "ST elevation," and "percutaneous coronary intervention." Only English language publications were included. A manual search for additional pertinent studies and review articles using references from retrieved articles was also completed.

\subsection{Study eligibility criteria}

Two main criteria were assessed for inclusion of studies. First was the reporting of incidence of major cardiovascular event (MACE) or allcause mortality in patients with STEMI who underwent $\mathrm{PCl}$ with and without fQRS. Second was reporting of relative risk, hazard ratio, odds ratio, incidence ratio, or standardized incidence ratio with $95 \%$ confidence intervals (or sufficient raw data for the calculation). Patients with STEMI who did not have fQRS were used as controls. Study

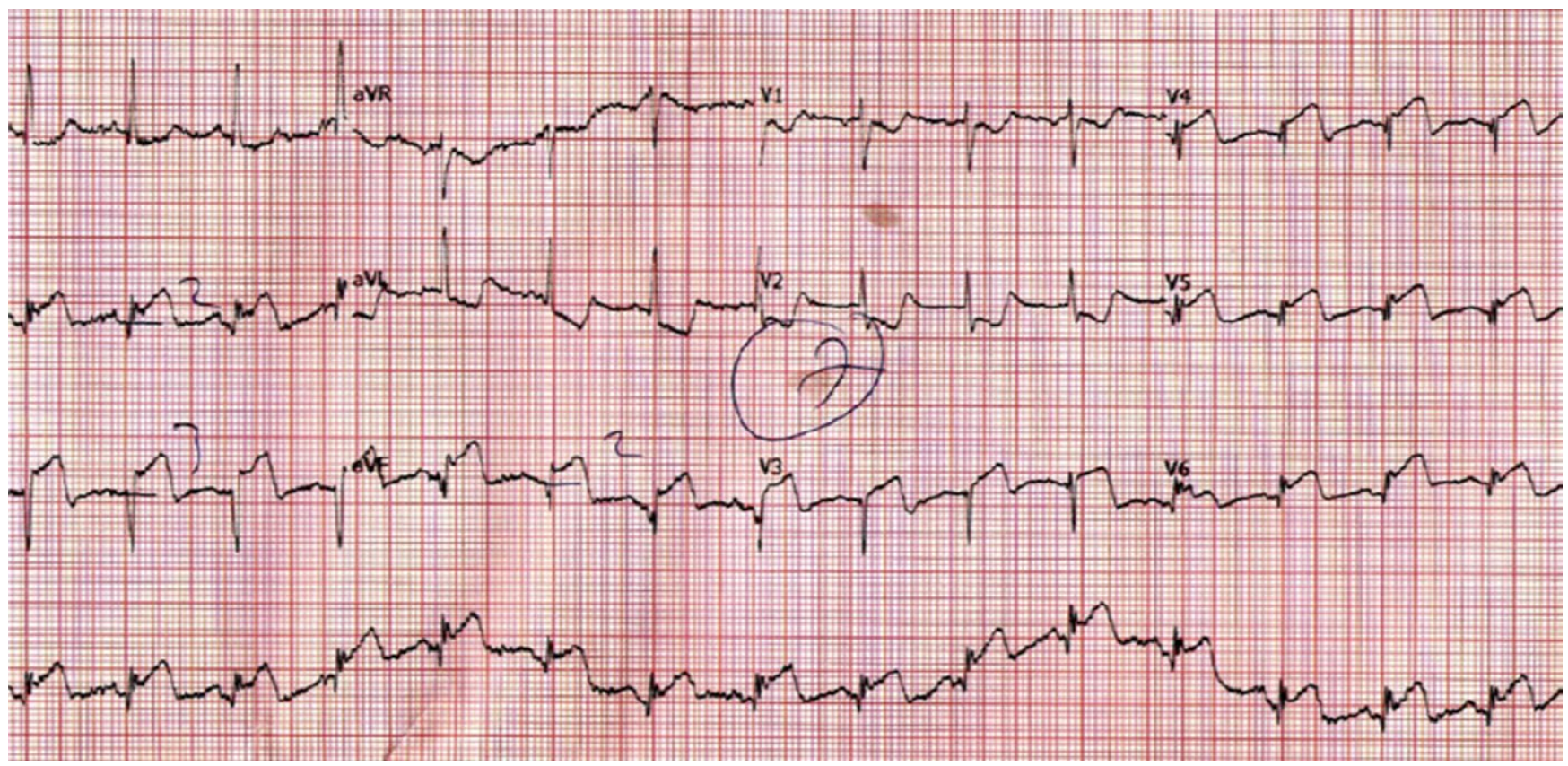

FIG URE 1 Electrocardiography demonstrating fragmented QRS complexes in lead V4, V5, V6 (Figure originally published in an article by Akgul et al. (2015), reproduced with permission from Wiley online library) 


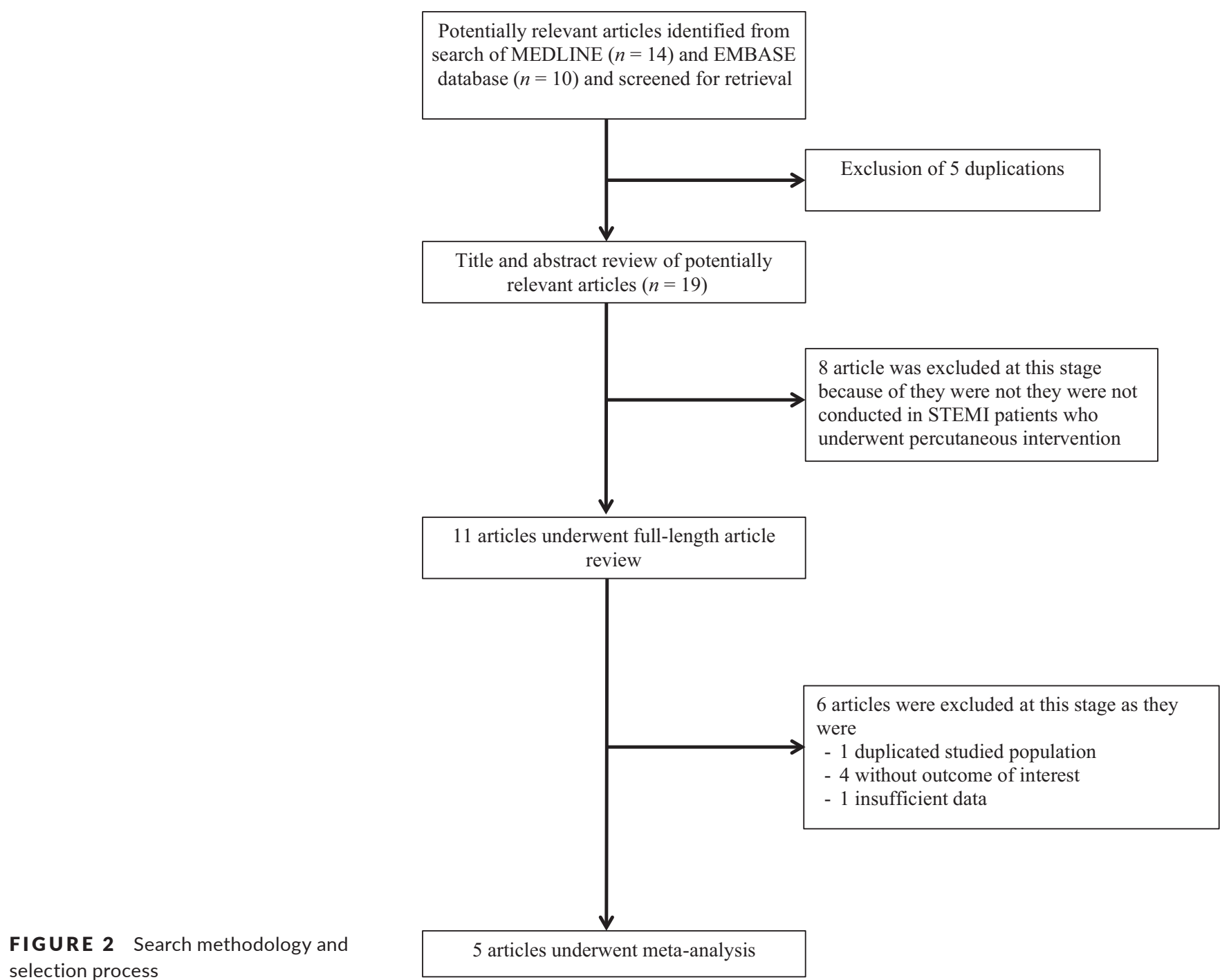

selection process

5 articles underwent meta-analysis

eligibility was independently determined by two investigators (NK and PC). Differences were resolved by mutual consensus. The NewcastleOttawa quality assessment scale was used to evaluate each study in three domains: recruitment and selection of the participants, similarity and comparability between the groups, and ascertainment of the outcome of interest among cohort studies (Stang, 2010).

\section{3 | Definition}

Fragmented QRS complexes were defined according to QRS morphologies described in each study. STEMI was defined as typical chest pain with the presence of ST segment elevation of $\geq 2 \mathrm{~mm}$ in two contiguous leads or as defined in each study. All-cause mortality was defined as deaths of any cause within follow-up time specified in each study.

\section{4 | Data extraction}

A standardized data collection form was used to obtain the following information from each study: title, name of first author, year of study, year of publication, country of origin, number of participants, demographic data of participants, method used to identify cases and controls, method used to diagnose the outcomes of interest (i.e., all-cause mortality), average duration of follow-up, adjusted and unadjusted risk ratios and their corresponding $95 \%$ confidence interval, and list of confounders that were adjusted for in multivariate analysis. To ensure accuracy, all investigators independently performed this data extraction process. Any data discrepancy was resolved by referring back to the original articles.

\subsection{Statistical analysis}

Meta-analysis of the combined data was performed using a random-effects, generic inverse variance method of DerSimonian and Laird (DerSimonian \& Laird, 1986). The heterogeneity of effect size estimates across these studies was quantified using the $I^{2}$ statistic and Q statistic. For the Q statistic, substantial heterogeneity was defined as $p<0.10$. The $I^{2}$ statistic ranges in value from $0 \%$ to $100 \%\left(I^{2}<25 \%\right.$, low heterogeneity; $I^{2}=25 \%-50 \%$, moderate heterogeneity; and $I^{2}>50 \%$, substantial heterogeneity; 


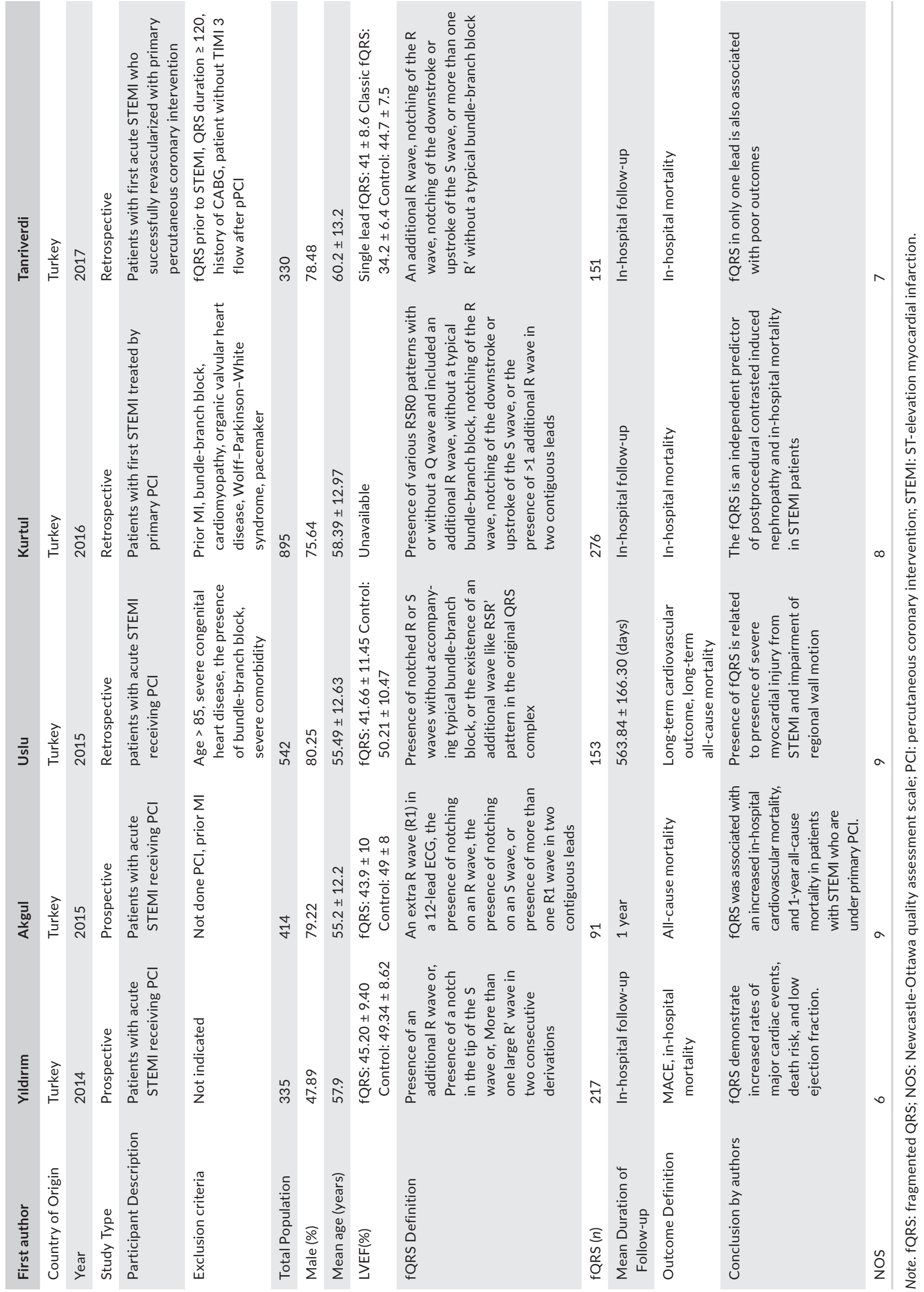


Higgins, Thompson, Deeks, \& Altman, 2003). A sequential exclusion strategy, as described by Patsopoulos and colleagues, was used to examine whether overall estimates were influenced by the substantial heterogeneity observed. We sequentially and cumulatively excluded studies that accounted for the largest share of heterogeneity until $I^{2}$ was $<50 \%$. We then examined whether relative risk estimates were consistent. In accordance with Cochrane, publication bias was assessed using funnel plot. Funnel plot asymmetry was further confirmed with Egger's test if there were more than 10 available studies (Sterne \& Egger, 2001). All analysis was performed using Review manager version 5.3 and STATA version 13.

\section{3 | RESULTS}

\section{1 | Description of included studies}

Our search strategy yielded 24 potentially relevant articles (10 articles from EMBASE and 14 articles from MEDLINE). After the exclusion of five duplicated articles, 19 articles underwent title and abstract review. Eight were excluded at this stage since they were not conducted in STEMI patients who underwent PCI, leaving 11 articles for full-length article review. One study was excluded, as this was a potentially duplicated studied population. Four studies were excluded because they did not report outcome of interest. Therefore, three retrospective and two prospective cohort studies with 888 fQRS and 1,628 non-fQRS STEMI patients were included in this meta-analysis (Akgul et al., 2015; Kurtul \& Duran, 2017; Tanriverdi, Dursun, Colluoglu, \& Kaya, 2017; Uslu et al., 2015; Yildirim et al., 2014). The clinical characteristics are described in Table 1.

\subsection{Quality assessment of included studies}

The Newcastle-Ottawa scale (0-9) was used to evaluate included studies on three domains: selection, comparability, and outcomes. Higher scores represent higher study quality. Four of five studies received a score of 7-9, which reflected high quality of included studies. One study received a score of 6 , indicating moderate quality study. Detailed evaluation of each study is presented in a Table S1.

\section{3 | Meta-analysis result}

A total of five studies (two prospective, three retrospective) with 2,516 participants were included in the meta-analysis. The incidence of fQRS was $35 \%$. There was an association between fQRS and allcause mortality in patients with STEMI who underwent PCI (RR 3.87; $95 \% \mathrm{Cl} 1.96-7.66)$ with moderate heterogeneity $\left(I^{2}=43 \%\right)$. Funnel plot is shown in Figure 3. Subgroup analysis of retrospective studies showed that the association remains significant (RR 3.38; 95\% $\mathrm{Cl} 1.45-7.87)$ with significant heterogeneity $\left(I^{2}=59 \%\right)$ comparing to prospective studies (RR 6.32; 95\% Cl 1.95-20.55). There was no subgroup difference between prospective and retrospective studies $\left(I^{2}=0 \%\right)$. Subgroup analysis of three studies (Kurtul \& Duran, 2017; Tanriverdi et al., 2017; Yildirim et al., 2014) with shorter follow-up time (in-hospital or short-term mortality) still shows significant association (RR 5.58; 95\% Cl 2.65-11.75) with low heterogeneity $\left(I^{2}=0 \%\right)$. Funnel plot did not suggest publication bias (Figure 4). Egger's test was not performed due to low number of the studies. Two studies reported successful rate of $\mathrm{PCl}$ by no-reflow. A study by Yildirim et al. (2014) reported no difference in the rate of no-reflow between patients with and without fQRS. However, Kurtul \& Duran (2017) reported higher rate of postprocedural no-reflow in patients
Risk ratio

Study or subgroup 1.1.1 Prospective

Akgul, 2015

Yildirim, 2014

Subtotal $(95 \% \mathrm{Cl})$

Heterogeneity: $\mathrm{Tau}^{2}=0.00 ; \mathrm{Chi}^{2}=0.46, d f=1(p=0.50) ; I^{2}=0 \%$

Test for overall effect: $Z=3.07(p=0.002)$
1.1.2 Retrospective

Uslu, 2015

Tanriverdi, 2017

Kurtul, 2016

Subtotal $(95 \% \mathrm{Cl})$

Heterogeneity: $\mathrm{Tau}^{2}=0.32 ; \mathrm{Chi}^{2}=4.85, d f=2(p=0.09) ; l^{2}=59 \%$

Test for overall effect: $Z=2.82(p=0.005)$

Total $(95 \% \mathrm{Cl})$

$100.0 \%$

$3.87[1.96,7.66]$

Heterogeneity: $\mathrm{Tau}^{2}=0.24 ; \mathrm{Chi}^{2}=7.06, d f=4(p=0.13) ; l^{2}=43 \%$

Test for overall effect: $Z=3.89(p<0.0001)$

Test for subgroup differences: $\mathrm{Chi}^{2}=0.72, d f=1(p=0.40), l^{2}=0 \%$
$1.86[1.04,3.33]$

$4.43[1.85,10.60]$

$9.06[1.72,47.72]$

$3.38[1.45,7.87]$
Risk ratio

IV, Random, 95\% Cl

FIG URE 3 Forest plot of studies comparing mortality in STEMI patients who underwent PCI, with and without fQRS. Horizontal lines represent the $95 \% \mathrm{Cls}$ with marker size reflecting the statistical weight of the study using random-effects model. A diamond data marker represents the overall adjusted odds ratio (OR) and $95 \% \mathrm{Cl}$ for the outcome of interest 


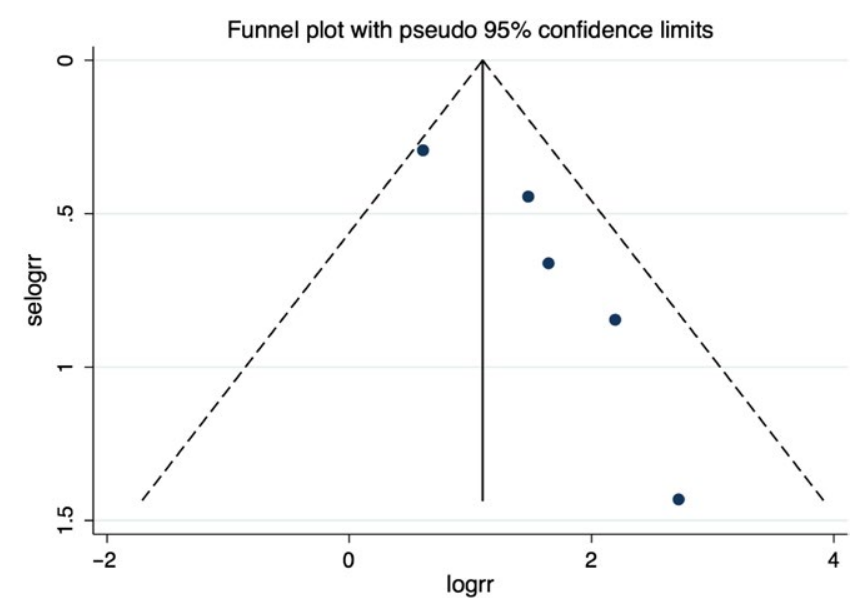

FIGURE 4 Funnel plot of fragmented QRS and mortality. Circles represent published studies

with fQRS than without fQRS ( $28 \%$ vs $13 \%$, consecutively). There was no difference in postprocedural TIMI flow in two studies (Akgul et al., 2015; Uslu et al., 2015). Tanriverdi et al. (2017) included only patients with successful $\mathrm{PCl}$ in their study. We conducted subgroup analyses to examine if these differences would affect the association. There remained a significant association with presence of fQRS and increased mortality after exclusion of a study by Tanriverdi et al. (RR 4.12; 95\% Cl 1.58-10.73; $I^{2}=51 \%$ ) and Kurtul et al. (RR 3.38; $\left.95 \% \mathrm{Cl} 1.68-6.81 ; I^{2}=43 \%\right)$.

\section{4 | DISCUSSION}

Our study found that incidence of fQRS can be as high as 35\% in STEMI patients who underwent $\mathrm{PCI}$. In patients with STEMI who underwent $\mathrm{PCl}$, those with $\mathrm{fQRS}$ on their ECG had increased mortality compared to patients without fQRS. The association remained significant after subgroup analyses of retrospective studies and studies with short follow-up time. Prior meta-analysis have been conducted in patients with both NSTEMI and STEMI and found that patients with $f Q R S$ has a higher rate of adverse events, including both longterm and short-term mortality and major adverse cardiovascular events (Gungor et al., 2016). Our meta-analysis focused only on STEMI patients who underwent $\mathrm{PCl}$ and found similar association with all-cause mortality, emphasizing the importance of fQRS as a potential prognostic factor of poor outcome.

The mechanism of the association between fQRS and mortality in STEMI has not been fully described in the literature. fQRS has been shown to be associated with multivessel involvement, the presence of myocardial scar, and left ventricular dysfunction (Das et al., 2008), all of which indicate poor prognosis in STEMI patients. fQRS has also been shown to be associated with ventricular arrhythmias (Das et al., 2010), which could be a potential factor that drives the association between $\mathrm{fQRS}$ and mortality.

To the best of our knowledge, this is the first systematic review and meta-analysis to examine the association between fQRS and increased mortality in STEMI patients, specifically those who underwent $\mathrm{PCl}$. Our findings will help physicians recognize STEMI patients with a potential for increased morbidity and mortality. fQRS could thus be integrated into a risk stratification strategy for patients with STEMI. Further studies are needed to determine the exact mechanism of the association and possible treatment options for this patient population.

\section{1 | Limitations}

There are limitations in our meta-analysis. Studies with different methodology and population were included. fQRS was defined differently across the studies. There are also differences in follow-up time between studies, resulting in a difference in the incidence of mortality. These limitations contributed to moderate heterogeneity in the meta-analysis. Success rates of $\mathrm{PCl}$ could potentially have effects on all-cause mortality. One study showed no significant difference in no-reflow post-PCl. Two studies showed no significant difference in post-PCI TIMI flow. However, one study showed higher no-reflow rate in patients with fQRS. One study only included patients with successful PCl. Thus, we did a subgroup analyses and found that the association remained significant despite exclusion of each of the two studies.

\section{5 | CONCLUSION}

In conclusion, our meta-analysis demonstrated an association between $\mathrm{fQRS}$ and mortality in STEMI patients undergoing PCl. These findings help emphasize the importance of surface ECG in the risk stratification of these patients. However, more studies are needed to examine the mechanism of this association and potential therapeutic interventions for this patient population.

\section{ACKNOWLEDGMENT}

None.

\section{CONFLICT OF INTEREST}

The authors declare that they have no conflicts of interest.

\section{AUTHOR CONTRIBUTION}

Pattara Rattanawong: Conception design, data interpretation, draft manuscript, and corresponding. Napatt Kanjanahattakij: Conception design, data interpretation, and draft manuscript. Tanawan Riangwiwat: Data acquisition and data interpretation. Narut Prasitlumkum: Data acquisition and draft manuscript. Nath Limpruttidham: Data acquisition and statistic analysis. Pakawat Chongsathidkiet: Data acquisition. Wasawat Vutthikraivit: Data interpretation. Erin Crossey: Language editing and proof reading. 


\section{ORCID}

Napatt Kanjanahattakij (iD http://orcid.org/0000-0002-4371-1625

Pattara Rattanawong (iD http://orcid.org/0000-0001-9419-5854

Narut Prasitlumkum iD http://orcid.org/0000-0002-7956-0574

Pakawat Chongsathidkiet (iD http://orcid.org/0000-0001-5363-3061

Wasawat Vutthikraivit iD http://orcid.org/0000-0003-1701-9800

\section{REFERENCES}

Akgul, O., Uyarel, H., Pusuroglu, H., Surgit, O., Turen, S., Erturk, M., ... Uslu, N. (2015). Predictive value of a fragmented QRS complex in patients undergoing primary angioplasty for ST elevation myocardial infarction. Annals of Noninvasive Electrocardiology, 20(3), 263272. https://doi.org/10.1111/anec.12179

Das, M. K., Khan, B., Jacob, S., Kumar, A., \& Mahenthiran, J. (2006). Significance of a fragmented QRS complex versus a $\mathrm{Q}$ wave in patients with coronary artery disease. Circulation, 113(21), 24952501. https://doi.org/10.1161/CIRCULATIONAHA.105.595892

Das, M. K., Maskoun, W., Shen, C., Michael, M. A., Suradi, H., Desai, M., ... Bhakta, D. (2010). Fragmented QRS on twelve-lead electrocardiogram predicts arrhythmic events in patients with ischemic and nonischemic cardiomyopathy. Heart Rhythm, 7(1), 74-80. https:// doi.org/10.1016/j.hrthm.2009.09.065

Das, M. K., Suradi, H., Maskoun, W., Michael, M. A., Shen, C., Peng, J., ... Mahenthiran, J. (2008). Fragmented wide QRS on a 12-lead ECG: a sign of myocardial scar and poor prognosis. Circulation: Arrhythmia and Electrophysiology, 1(4), 258-268.

DerSimonian, R., \& Laird,N.(1986). Meta-analysisinclinicaltrials.Controlled Clinical Trials, 7(3), 177-188. https://doi.org/10.1016/0197-2456 (86) $90046-2$

Gungor, B., Ozcan, K. S., Karatas, M. B., Sahin, I., Ozturk, R., \& Bolca, O. (2016). Prognostic value of QRS fragmentation in patients with acute myocardial infarction: a meta-analysis. Annals of Noninvasive Electrocardiology, 21(6), 604-612. https://doi.org/10.1111/ anec.12357

Higgins, J. P., Thompson, S. G., Deeks, J. J., \& Altman, D. G. (2003). Measuring inconsistency in meta-analyses. BMJ, 327(7414), 557560. https://doi.org/10.1136/bmj.327.7414.557

Kristensen, S. D., Laut, K. G., Fajadet, J., Kaifoszova, Z., Kala, P., Di Mario, C., ... European Association for Percutaneous Cardiovascular Interventions (2014). Reperfusion therapy for ST elevation acute myocardial infarction 2010/2011: current status in 37 ESC countries. European Heart Journal, 35(29), 1957-1970. https://doi. org/10.1093/eurheartj/eht529

Kurtul, A., \& Duran, M. (2017). Fragmented QRS complex predicts contrast-induced nephropathy and in-hospital mortality after primary percutaneous coronary intervention in patients with ST-segment elevation myocardial infarction. Clinical Cardiology, 40(4), 235-242. https://doi.org/10.1002/clc.22651

Pedersen, F., Butrymovich, V., Kelbaek, H., Wachtell, K., Helqvist, S., Kastrup, J., ... Jørgensen, E. (2014). Short- and long-term cause of death in patients treated with primary $\mathrm{PCl}$ for STEMI. Journal of the American College of Cardiology, 64(20), 2101-2108. https://doi. org/10.1016/j.jacc.2014.08.037

Rosengarten, J. A., Scott, P. A., \& Morgan, J. M. (2015). Fragmented QRS for the prediction of sudden cardiac death: a meta-analysis. Europace, 17(6), 969-977. https://doi.org/10.1093/europace/euu279

Stang, A. (2010). Critical evaluation of the Newcastle-Ottawa scale for the assessment of the quality of nonrandomized studies in metaanalyses. European Journal of Epidemiology, 25(9), 603-605. https:// doi.org/10.1007/s10654-010-9491-z

Sterne, J. A., \& Egger, M. (2001). Funnel plots for detecting bias in meta-analysis: guidelines on choice of axis. Journal of Clinical Epidemiology, 54(10), 1046-1055. https://doi.org/10.1016/ S0895-4356(01)00377-8

Tanriverdi, Z., Dursun, H., Colluoglu, T., \& Kaya, D. (2017). Single derivation fragmented QRS can predict poor prognosis in successfully revascularized acute STEMI patients. Arquivos Brasileiros de Cardiologia, 109(3), 213-221.

Uslu, N., Gul, M., Cakmak, H. A., Atam, A., Pusuroglu, H., Satilmisoglu, H., ... Eksik, A. (2015). The assessment of relationship between fragmented QRS complex and left ventricular wall motion score index in patients with ST elevation myocardial infarction who underwent primary percutaneous coronary intervention. Annals of Noninvasive Electrocardiology, 20(2), 148-157. https://doi. org/10.1111/anec.12180

Yildirim, E., Karaçimen, D., Özcan, K. S., Osmonov, D., Türkkan, C., Altay, S., ... Erdinler, I. (2014). The relationship between fragmentation on electrocardiography and in-hospital prognosis of patients with acute myocardial infarction. Medical Science Monitor, 20, 913-919.

\section{SUPPORTING INFORMATION}

Additional supporting information may be found online in the Supporting Information section at the end of the article.

How to cite this article: Kanjanahattakij N, Rattanawong P, Riangwiwat T, et al. Fragmented QRS and mortality in patients undergoing percutaneous intervention for ST-elevation myocardial infarction: Systematic review and meta-analysis. Ann Noninvasive Electrocardiol. 2018;23:e12567. https://doi.org/10.1111/anec.12567 